\title{
Wnt signaling*
}

\section{David M. Eisenmann ${ }^{\S}$, Department of Biological Sciences, University of Maryland Baltimore County, Baltimore, MD 21250 USA}

\section{Table of Contents}

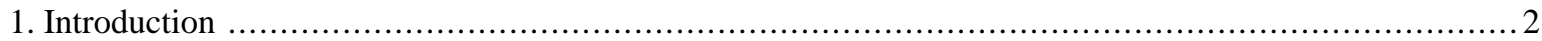

2. Canonical and noncanonical Wnt signaling in flies and vertebrates ..........................................

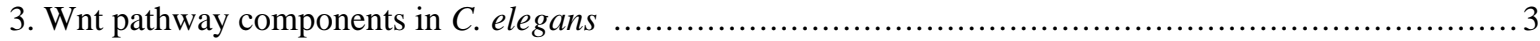

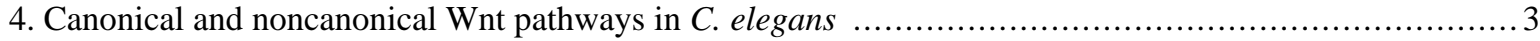

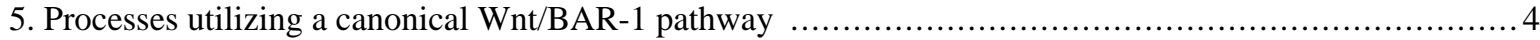

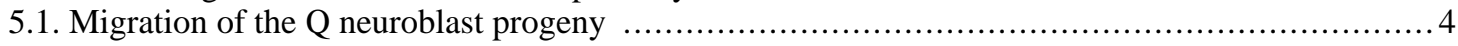

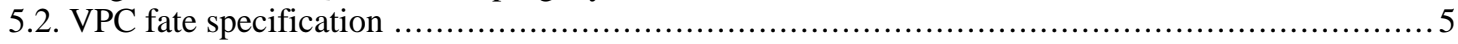

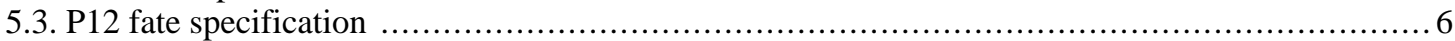

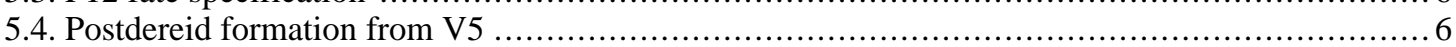

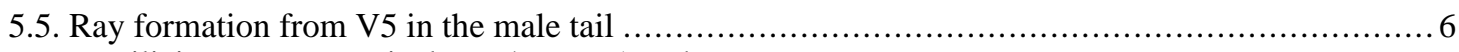

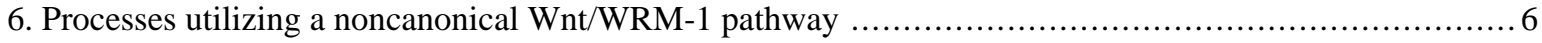

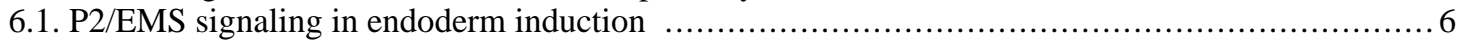

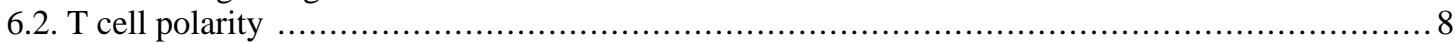

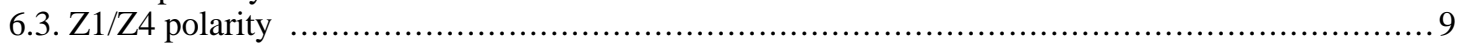

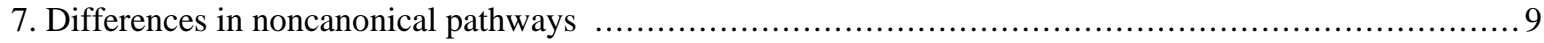

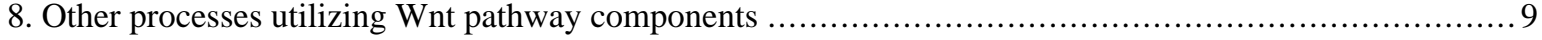

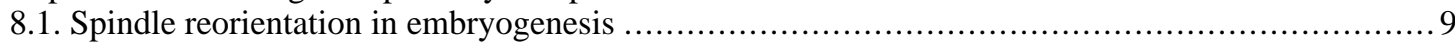

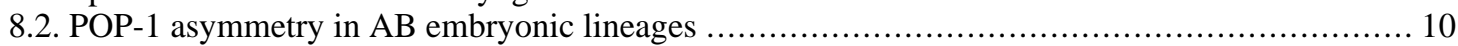

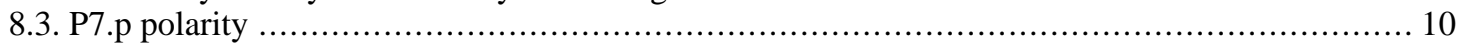

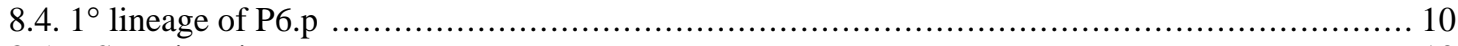

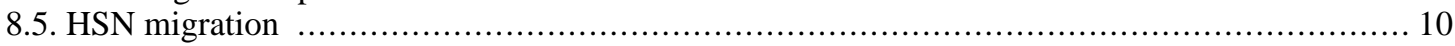

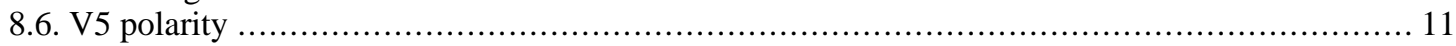

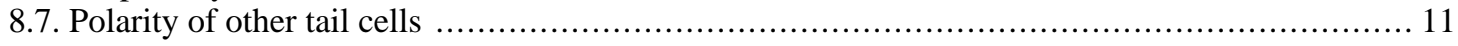

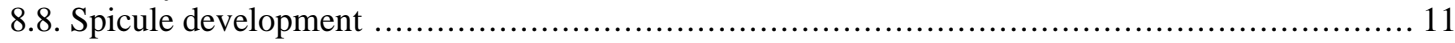

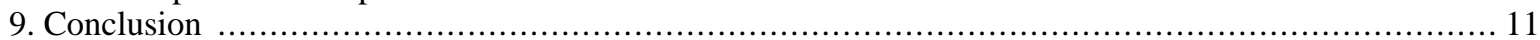

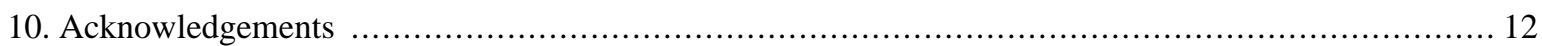

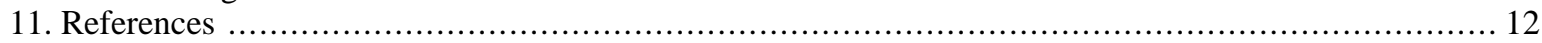

\begin{abstract}
The use of Wnt ligands for signaling between cells is a conserved feature of metazoan development. Activation of Wnt signal transduction pathways upon ligand binding can regulate diverse processes including
\end{abstract}

\footnotetext{
${ }^{*}$ Edited by Iva Greenwald. Last revised June 13, 2005. Published June 25, 2005. This chapter should be cited as: Eisenmann, D. M., Wn signaling (June 25, 2005), WormBook, ed. The C. elegans Research Community, WormBook, doi/10.1895/wormbook.1.7.1, http://www.wormbook.org.

Copyright: ( 92005 David M. Eisenmann. This is an open-access article distributed under the terms of the Creative Commons Attribution License, which permits unrestricted use, distribution, and reproduction in any medium, provided the original author and source are credited ${ }^{\S}$ To whom correspondence should be addressed. E-mail: eisenman@umbc.edu
} 
cell proliferation, migration, polarity, differentiation and axon outgrowth. A 'canonical' Wnt signaling pathway has been elucidated in vertebrate and invertebrate model systems. In the canonical pathway, Wnt binding leads to the stabilization of the transcription factor $\beta$-catenin, which enters the nucleus to regulate Wnt pathway target genes. However, Wnt binding also acts through $\beta$-catenin-independent, noncanonical pathways, such as the planar cell polarity (PCP) pathway and a pathway involving $\mathrm{Ca}^{2+}$ signaling. This chapter examines our current understanding of Wnt signaling and Wnt-mediated processes in the nematode C. elegans. Like other species, the $C$. elegans genome encodes multiple genes for Wnt ligands (five) and Wnt receptors (four frizzleds, one Ryk/Derailed). Unlike vertebrates or Drosophila, the C. elegans genome encodes three $\beta$-catenin genes, which appear to have distinct functions in Wnt signaling and cell adhesion. Canonical Wnt signaling clearly exists in C. elegans, utilizing the $\beta$-catenin BAR-1. However, a noncanonical pathway utilizing the $\beta$-catenin WRM-1 also exists, and to date a similar pathway has not been described in other species. Evidence for $\beta$-catenin independent noncanonical Wnt signaling is currently limited. The role of Wnt signaling in over a dozen $C$. elegans developmental processes, including the regulation of cell fate, polarity and migration, is described.

\section{Introduction}

The Wnt extracellular signaling pathway (wingless in Drosophila) is one of a handful of evolutionarily-conserved signal transduction pathways used extensively during animal development, from Hydra to humans (Cadigan and Nusse, 1997; Wodarz and Nusse, 1998; Hobmayer et al., 2000; Peifer and Polakis, 2000). Wnt signals control multiple aspects of development, including the proliferation, fate specification, polarity, and migration of cells. In addition, overactivation of Wnt signaling by mutation is a major factor in oncogenesis in the human colon and other tissues (Polakis, 2000). Work in Drosophila and vertebrates has shown that Wnt signals are transduced in at least two distinct ways; a well-established 'canonical' or Wnt//-catenin pathway, and a noncanonical pathway or pathways that are $\beta$-catenin independent.

\section{Canonical and noncanonical Wnt signaling in flies and vertebrates}

A recent survey of known components in or associated with canonical Wnt signaling pathways lists over 50 proteins (see www.stanford.edu/ rnusse/pathways/cell2.html). Due to this complexity, this review will focus only on well-established, core components of the pathway (for review, see Wodarz and Nusse, 1998; Peifer and Polakis, 2000). A major effector of the canonical Wnt signaling pathway is the transcription factor $\beta$-catenin (Armadillo in flies; Figure 1). In the absence of ligand, cytoplasmic $\beta$-catenin interacts with APC and Axin scaffold proteins and is a substrate for the kinases CKI and GSK3 $\beta$. Phosphorylated $\beta$-catenin is then ubiquitinated and destroyed by the proteosome. When Wnt ligand binds to a Frizzled family receptor and a coreceptor of the LRP-5/6/arrow family, the APC/Axin/CK1/GSK3 $\beta$ destruction complex is inhibited, leading to the stabilization of $\beta$-catenin and its translocation to the nucleus where it interacts with TCF/LEF family transcription factors. In the absence of signal, TCF/LEF factors bind DNA at Wnt-responsive genes and interact with other factors (e.g. Groucho, histone deacetylase) to repress transcription. $\beta$-catenin binding to TCF/LEF proteins provides a transcription activation domain so target gene expression is activated.

Noncanonical Wnt signaling pathways in Drosophila and vertebrates are less well understood, but appear to function in a $\beta$-catenin independent manner to regulate processes such as convergent extension during vertebrate gastrulation, and the polarity of hairs, bristles and ommatidia in Drosophila (for review, see, Kuhl et al., 2000; Peifer and Polakis, 2000; Veeman et al., 2003). These noncanonical pathways have also been termed the $\mathrm{Wnt} /$ Calcium and Wnt/JNK pathways in vertebrates and the Wnt/planar cell polarity pathway (PCP) in flies. The similarity of these pathways to each other is under intense investigation, and a discussion of their molecular details is beyond the scope of this review. Briefly, activation of the Wnt/Calcium pathway involves Wnt binding to a Frizzled receptor, leading to release of intracellular calcium and the activation of enzymes such as CamKII and PKC (Kuhl et al., 2000). The Wnt/Jnk and PCP pathways appear to be similar in utilizing Frizzled receptors, Dishevelled, JNK and Rho family GTPases (Veeman et al., 2003). While Wnts are used in the vertebrate Wnt/Jnk pathway, no Wnt ligand has been identified for the Drosophila PCP pathway. Currently, the conservation of function of these pathways in C. elegans is unclear. 


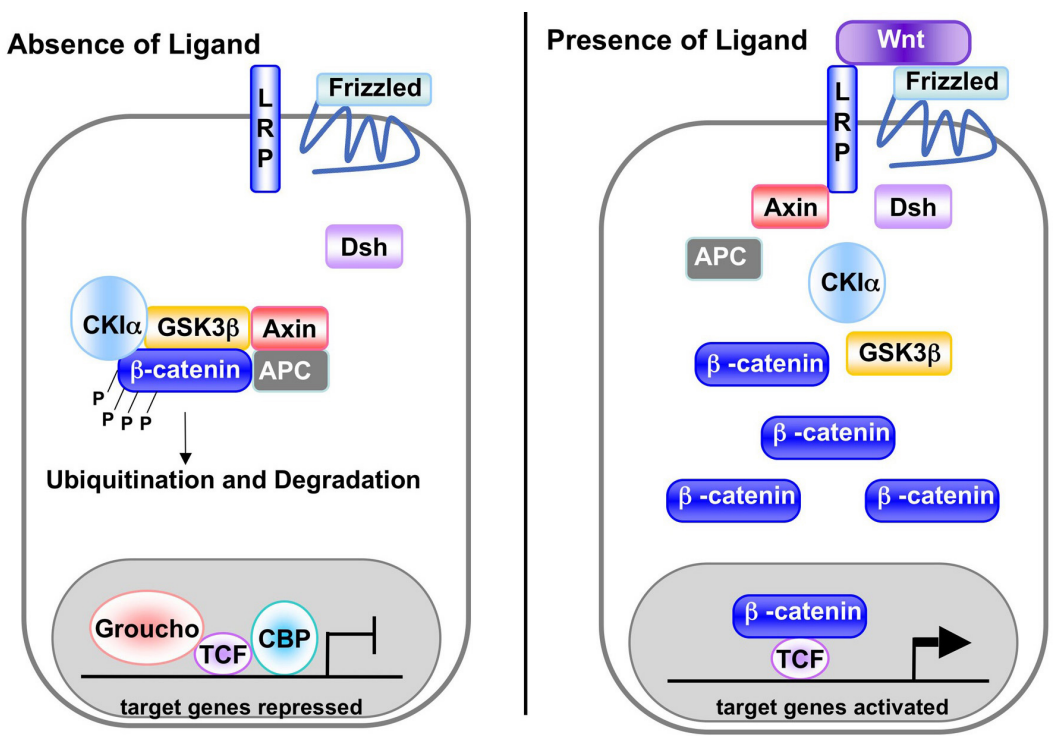

Figure 1. A canonical Wnt signaling pathway. In the absence of signal, action of the destruction complex (CKI $\alpha$, GSK3 $\beta$, APC, Axin) creates a hyperphosphorylated $\beta$-catenin, which is a target for ubiqitination and degradation by the proteosome. Binding of Wnt ligand to a Frizzled/LRP-5/6 receptor complex leads to stabilization of hypophosphorylated $\beta$-catenin, which interacts with TCF/LEF proteins in the nucleus to activate transcription. In a canonical pathway, CKI $\alpha$, GSK3 $\beta$, APC, and Axin act as negative regulators and all other components act positively.

\section{Wnt pathway components in C. elegans}

C. elegans has a complement of canonical Wnt pathway components similar to those in flies and vertebrates, but with some notable differences (Ruvkun and Hobert, 1998). Like those species, C. elegans has multiple genes encoding Wnt ligands (lin-44, egl-20, mom-2, cwn-1 and cwn-2; (Shackleford et al., 1993; Herman et al., 1995; Rocheleau et al., 1997; Thorpe et al., 1997; Maloof et al.,1999), Frizzled family Wnt receptors (lin-17, mom-5, mig-1 and cfz-2 (Sawa et al., 1996; Rocheleau et al., 1997; Ruvkun and Hobert, 1998; Herman, 2003), and Disheveled proteins (mig-5, $d s h-1, d s h-2$; Ruvkun and Hobert, 1998). The worm genome also encodes homologs of Porcupine (mom-1) (Rocheleau et al., 1997), Casein Kinase I $\alpha$ (kin-19) (Peters et al., 1999), GSK3ß (gsk-3) (Schlesinger et al., 1999), and Axin (pry-1) (Korswagen et al., 2002). Unlike other species, C. elegans has three genes encoding divergent $\beta$-catenin proteins (bar-1, wrm-1 and hmp-2; Rocheleau et al., 1997; Costa et al., 1998; Eisenmann et al., 1998), with the multiple functions of $\beta$-catenin dispersed among the three homologs (Korswagen et al., 2000; Natarajan et al., 2001). Also, worms appear to have only a single TCF/LEF gene, pop-1, and a single APC gene, apr-1(Rocheleau et al., 1997). Finally, to date no gene encoding a clear LRP-5/6/Arrow homolog has been identified, although caution is advised since nematode Wnt pathway genes are quite diverged, and an axin-encoding gene was initially overlooked. The worm genome encodes homologs of the Wnt pathway regulators Nlk (lit-1; Meneghini et al., 1999; Rocheleau et al., 1999), TAK1 (mom-4; Meneghini et al., 1999; Shin et al., 1999) and TAB1 (tap-1; Meneghini et al., 1999), and the recently identified Wnt receptor Ryk/Derailed (lin-18; Inoue et al., 2004).

\section{Canonical and noncanonical Wnt pathways in C. elegans}

The first well-characterized Wnt pathway in C. elegans was a noncanonical pathway that mediates a signal from P2 to EMS required for endoderm formation (see below). In this pathway, the homologs of APC, GSK3 $\beta$ and TCF behave in an opposite manner from similar proteins in other species, suggesting that Wnt signaling was fundamentally different in worms (Han, 1997). Subsequent work showed that both canonical and noncanonical Wnt signaling pathways exist in C. elegans. To date, it appears that processes utilizing the $\beta$-catenin homolog BAR-1 use a canonical Wnt pathway like that found in other species, while processes involving the $\beta$-catenin homolog WRM-1 use a noncanonical Wnt pathway that is distinct from noncanonical pathways in vertebrates. Like other $\beta$-catenins, BAR-1 interacts directly with an amino terminal domain of POP-1/TCF, and can activate transcription in yeast (Korswagen et al., 2000; Natarajan et al., 2001). WRM-1 however, does not appear to interact strongly with POP-1/TCF, and activates transcription less well than BAR-1 in vitro and in a yeast system (Korswagen et al., 2000; Natarajan et al., 2001). Other Wnt signaling components, such as Wnt receptors, APR-1/APC, GSK-3/GSK3 $\beta$ and POP-1/TCF function in both types of pathways, but can behave differently depending on whether the process is 
controlled in a canonical or noncanonical manner. Several recent reviews have discussed canonical and noncanonical Wnt signaling in C. elegans (Korswagen, 2002; Herman, 2003; Herman and Wu, 2004).

\section{Processes utilizing a canonical Wnt/BAR-1 pathway}

A substantial body of evidence suggests that canonical Wnt signaling pathways similar to those in flies and vertebrates act in two post-embryonic processes, the control of QL progeny migration and VPC fate specification. Two other processes, P12 fate specification and contact mediated inhibition of gene expression in posterior seam cells, may also use a canonical pathway. Interestingly, all of these pathways utilize the $\beta$-catenin BAR- 1 and have a Hox gene as a downstream target.

\subsection{Migration of the $Q$ neuroblast progeny}

The QL and QR neuroblasts are born at the same position along the anterior/posterior $(\mathrm{A} / \mathrm{P})$ axis, on the left and right sides. These two cells produce similar progeny in the L1, but their descendants migrate in opposite directions, in a manner dependent on the Hox gene mab-5 (Sulston and Horvitz, 1977; Chalfie and Sulston, 1981; Kenyon, 1986). The mab-5 expressing QL progeny (QL.d) migrate further into the posterior, while the QR progeny (QR.d), which do not express mab-5, migrate toward the anterior (Figure 2). In mab-5 loss-of-function mutants, all cells migrate anteriorly, while in a mab-5 gain-of-function mutant they migrate posteriorly (Chalfie et al., 1983; Kenyon, 1986; Salser and Kenyon, 1992).

\section{mab-5 not expressed}
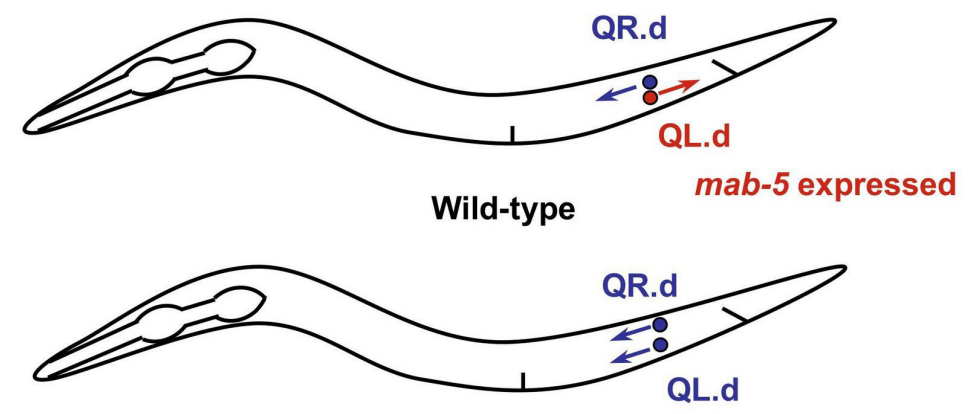

mig-14, egl-20, mig-1, lin-17, mig-5, bar-1, pop-1, mab-5(If), overexpression of sgg-1 or pry-1

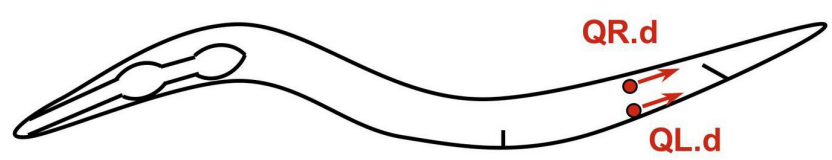

pry-1, mab-5(gf)

Figure 2. Canonical Wnt signaling in Q progeny. In wild-type animals the descendants of the neuroblast QR (QR.d) express the Hox gene mab-5 and migrate into the posterior, while the descendant of the sister cell QL (QL.d) do not express mab-5 and migrate into the anterior. In most Wnt pathway mutants, or in animals overexpressing the negative regulators $g s k-3 / G S K 3 b$ or pry-1/axin, the QR.d and the QL.d migrate into the anterior. In pry-1/axin and $m a b-5(g f)$ mutant animals, both the QR.d and the QL.d migrate into the posterior.

The expression of mab-5 in the QL progeny is controlled by a canonical Wnt pathway. The ligand for this pathway is EGL-20, with high levels of Wnt signal promoting posterior migration. Interestingly, the Q neuroblasts are not exposed to different levels of signal, rather the two cells have differing sensitivities to Wnt, such that the Wnt pathway is activated in QL.d, but not QR.d (Whangbo and Kenyon, 1999). Factors acting positively in this process are EGL-20/Wnt, LIN-17/Fz, MIG-1/Fz, MIG-5/Dsh, BAR-1/ $\beta$-cat, and POP-1/TCF (Harris et al., 1996; Maloof et al., 1999; Eisenmann and Kim, 2000; Korswagen et al., 2000; Herman, 2001; Figure 3). Loss of function for these genes leads to lack of mab-5 expression and anterior migration of the QL.d. Also, overexpression of gsk-3/GSK3 $\beta$ or pry-1/axin leads to anterior QL.d migration (Korswagen et al., 2002). Conversely, mutation of pry-1/axin causes expression of mab-5 in the QR.d and posterior migration (Figure 2). These results suggest that PRY-1/Axin and GSK-3/GSK3 $\beta$ act negatively in this pathway, as in other canonical Wnt pathways. 


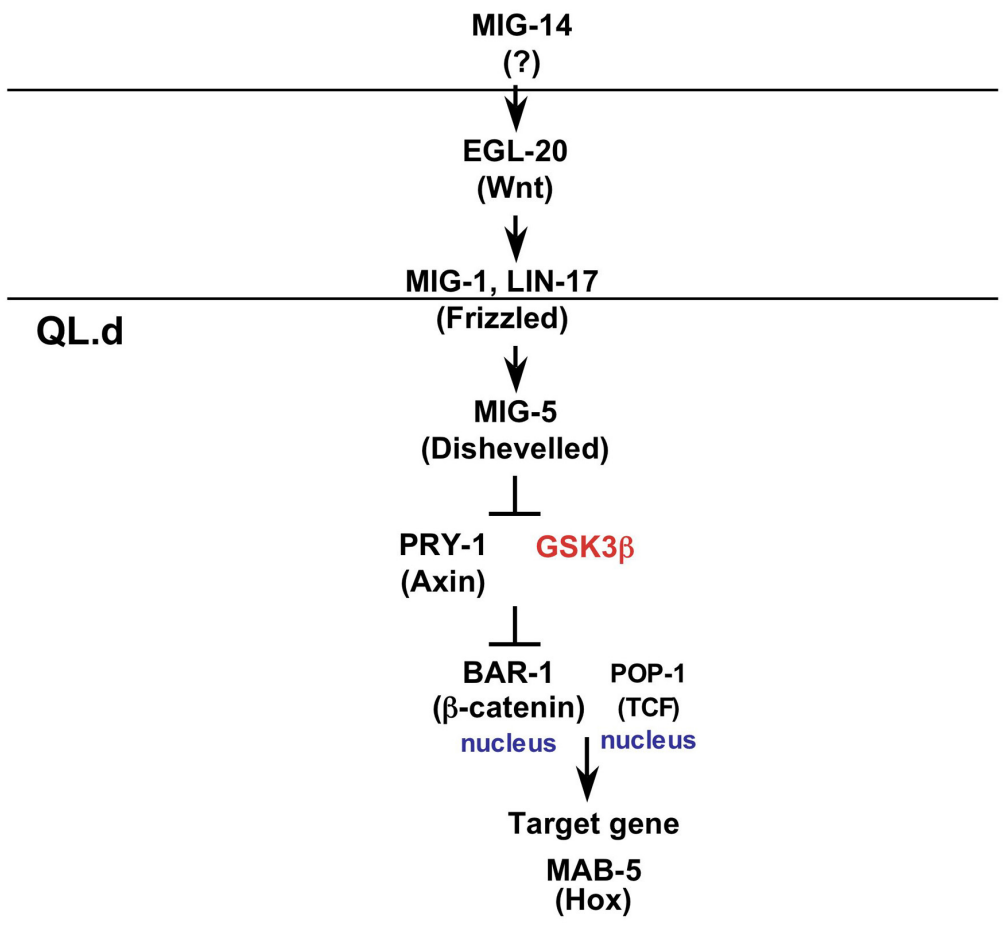

Figure 3. Canonical Wnt pathway in Q progeny. Proteins functioning in the canonical Wnt pathway active in the QL progeny are shown. Homologous vertebrate protein names are shown in parenthesis. The two horizontal lines indicate the plasma membranes of the signaling cell (top line) and QL.d (bottom line). The MIG-14/MOM-3 locus has not been identified yet, but acts in the signaling cell in P2-EMS signaling, so is shown in that position here. Active kinases are shown in red. The exact position of some components in the pathway, when not clear from epistasis experiments, is based on analogy to canonical pathways in other species.

Recently, it was shown that overexpression of the full length Ror receptor tyrosine kinase CAM-1, or the CAM-1 extracellular cysteine rich domain (which bind Wnts in Frizzled receptors) causes reduction of mab-5 expression and anterior migration of the QL.d (Kim and Forrester, 2003; Forrester et al., 2004). It is possible that CAM-1 serves as a sink for EGL-20 signal along the A/P axis, restricting its diffusion into the anterior. Finally, mutations in the genes mig-14, qid-5, qid-6, qid-7 and qid-8 also cause anterior migration of the QL.d, but are currently uncloned (Ch'ng et al., 2003).

\subsection{VPC fate specification}

The six vulval precursor cells (VPCs), P3.p - P8.p, are born in the ventral midbody region and express the Hox gene lin-39. They are competent to adopt one of three cell fates, $1^{\circ}, 2^{\circ}$, or $3^{\circ} .1^{\circ}$ and $2^{\circ}$ cells divide to generate cells that form the vulval opening, while $3^{\circ}$ cells divide once and fuse with the hyp 7 syncytium (for review, see Greenwald, 1997; Kornfeld, 1997). The VPCs always adopt their fates in the pattern $3^{\circ} 3^{\circ} 2^{\circ} 1^{\circ} 2^{\circ} 3^{\circ}$ or $\mathrm{F} 3^{\circ} 2^{\circ} 1^{\circ}$ $2^{\circ} 3^{\circ}$, where $\mathrm{F}$ indicates fusion with hyp7 without division. This patterning is mediated by an inductive signal from the anchor cell that activates a Ras pathway in P6.p (adopts $1^{\circ}$ fate), and lateral signals from P6.p that activate a Notch pathway in P5.p and P7.p (adopt $2^{\circ}$ fates). A canonical Wnt signaling pathway acts in the VPCs to allow the VPCs to adopt the $1^{\circ}, 2^{\circ}$ or $3^{\circ}$ cell fates correctly. When this pathway is compromised, many VPCs adopt $\mathrm{F}$ or $3^{\circ}$ fates, leading to defects in vulval induction (Eisenmann et al., 1998). Overactivation of this pathway leads to extra VPCs adopting vulval fates (Gleason et al., 2002). This pathway has been shown to use bar-1/3-cat, pry-1/axin, apr-1/APC and pop-1/TCF, and these genes behave in a canonical fashion where pry-1/axin and apr-1/APC act negatively (although see Hoier et al., 2000) and bar-1/ß-cat and pop-1/TCF act positively (Eisenmann et al., 1998; Gleason et al., 2002). The Wnt signal(s) and receptors controlling this pathway remain to be identified, but genetic redundancy is highly likely. One target of this pathway is the Hox gene lin-39. In bar- $1 / \beta$-cat mutants, lin-39 expression is lost in cells adopting the $\mathrm{F}$ fate, and forced expression of lin-39 can partially rescue bar-1/ $\beta$-cat mutants. Interestingly, the Ras pathway is also required for regulation of lin-39 in the VPCs, and when both the Wnt and Ras pathways are compromised, most VPCs adopt the F fate, suggesting this is the default fate for the VPCs in the absence of Wnt and Ras signals. 


\subsection{P12 fate specification}

The posterior hypodermal cells P11 and P12 migrate into the ventral midline from left and right lateral positions during the L1 stage and divide in different patterns (Sulston and Horvitz, 1977). Either cell can adopt the P12 fate before migration, but the right side cell usually does in wild type animals (Sulston and White, 1980). As with VPC fate specification, a Wnt pathway and an RTK/Ras pathway interact to regulate expression of a Hox gene (egl-5) to determine the P12 fate (Jiang and Sternberg, 1998; Eisenmann and Kim, 2000). The Wnt pathway utilizes lin-44/Wnt, lin- $17 / \mathrm{Fz}$ and bar-1/ß-cat, and the Ras pathway is similar to that used in vulval induction. Both this process and VPC fate specification utilize the downstream transcriptional regulators eor-1 (encodes a BTB/zinc finger protein) and eor-2 (novel) (Howard and Sundaram, 2002). Mutation of the $t c l-2$ gene, which encodes a novel protein acting in the T and Z1/Z4 polarity pathways (below), also causes defects in P12 fate specification (Zhao et al., 2003).

\subsection{Postdereid formation from V5}

The hermaphrodite lateral seam cells, V1 - V6 and T, divide during larval life in a stem cell pattern to give seam cells and cells that fuse with the hypodermal syncytium (Sulston and Horvitz, 1977). For most V cells, the Vn.pa daughter is a seam cell, but for V5, the V5.pa cell divides to generate a sensory structure called the postdereid. The ability of V5 to generate the postdereid in either sex depends on contacts between V cells (Sulston and White, 1980; Waring and Kenyon, 1990, 1991; Waring et al., 1992; Austin and Kenyon, 1994; Harris et al., 1996), and proper regulation of mab-5 (Kenyon, 1986; Salser and Kenyon, 1996). When V cells anterior or posterior to V5 are ablated, V5.pa makes a seam cell instead of a postdereid. Ablation of neighboring seam cells leads to ectopic expression of mab-5 in V5.pa (Hunter et al., 1999). The ectopic expression of mab-5 in V5.pa is due to the activation of a Wnt pathway involving egl-20/Wnt, lin-17/Fz, and bar-1/ $\beta$-cat, since mutations in these genes prevent the V5.pa cell fate transformation caused by V6 ablation (Hunter et al.,1999). Further, in pry-1/axin mutants, mab-5 is ectopically expressed in V5.pa and no postdereid is made (Maloof et al., 1999). These results suggest that contacts between V5.p and other seam cells leads to the inhibition of a Wnt pathway that would otherwise be active in V5 and induce $m a b-5$ expression. This Wnt pathway is likely to be a canonical pathway based on the bar-1/ß-cat and pry-1/axin results. How cell contacts lead to Wnt pathway inhibition is currently unknown.

\subsection{Ray formation from $\mathrm{V} 5$ in the male tail}

In the male, V5, V6 and T divide to generate the sensory rays (Sulston and Horvitz, 1977; Sulston et al., 1980). Proper ray formation requires mab-5 expression in V5 and V6, and is regulated by interactions between the seam cells (Sulston and White, 1980; Waring and Kenyon, 1990; Chow and Emmons, 1994; Salser and Kenyon, 1996). Specifically, following ablation of V6 in males, V5 now expresses mab-5 earlier than usual and adopts the V6 fate (Hunter et al., 1999). It is likely that a canonical Wnt pathway is required for this V5 fate transformation when V6 is ablated, since mutations in egl-20/Wnt and bar-1/B-cat suppress the fate transformation (Hunter et al., 1999). In pry-1/axin mutants, anterior $\mathrm{V}$ cells express mab-5 and generate rays, and formation of these ectopic rays requires bar-1/ß-cat and mab-5 activity (Maloof et al., 1999). Inhibition of the activity of this Wnt pathway by cell contact requires $d p y-22 / s o p-1 / m d t-12$ and sop-3/mdt-1.1, which encode homologs of the transcriptional Mediator complex components MED12/TRAP230 and MED1/TRAP220, respectively (Zhang and Emmons, 2000, 2001; Moghal and Sternberg, 2003; Bourbon et al., 2004). Direct or indirect targets of this Wnt pathway include the caudal homolog pal-1, and the Hox genes mab-5 and egl-5. Therefore, in both sexes, cell contacts between seam cells appear to inhibit Wnt signaling.

\section{Processes utilizing a noncanonical Wnt/WRM-1 pathway}

In a number of $C$. elegans Wnt-mediated processes the Wnt pathway components act in a manner different from a canonical Wnt signaling pathway. Unlike vertebrates, where noncanonical Wnt signaling does not use either a $\beta$-catenin or a TCF/LEF protein, these $C$. elegans pathways all utilize $w r m-1 / \beta$-cat, pop-1/TCF and the Nemo-like kinase LIT-1/Nlk.

\subsection{P2/EMS signaling in endoderm induction}

One of the best-studied Wnt-mediated processes is the signal from the P2 cell to the EMS cell at the four-cell stage of embryogenesis, which polarizes EMS to divide into an anterior MS daughter that produces mesodermal tissues and a posterior E daughter that produces endoderm (Figure 4). 


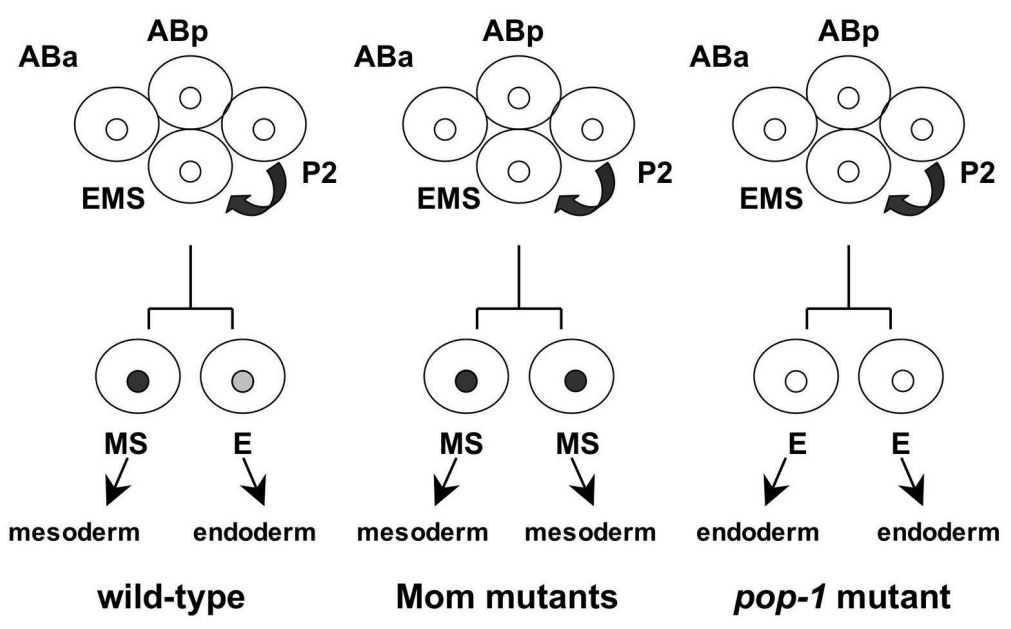

Figure 4. P2-EMS Signaling. The top line shows the four blastomeres at the four cell stage of embryogenesis, and an arrow indicates the P2 to EMS signal required for endoderm induction. The bottom line shows the two daughters of the EMS division. In wild-type, EMS divides to give an anterior daughter (MS) with higher nuclear POP-1 levels (dark circle) that generates mesodermal tissues, and a posterior daughter (E) with lower nuclear POP-1 levels (light circle) that generates only endoderm. In mutants giving a Mom phenotype, two MS-like daughters are born, with higher nuclear POP-1 levels. In a pop-1 mutant, two E-like daughters are born.

Blastomere isolation and recombination experiments indicated that a signal from P2 is required for EMS to produce endoderm (Goldstein, 1992, Goldstein, 1993). Forward and reverse genetic screens identified the components of a Wnt pathway acting in this process (Lin et al., 1995; Kaletta et al., 1997; Rocheleau et al., 1997; Thorpe et al., 1997) (Figure 5). This pathway utilizes mom-1/porcupine, mom-2/Wnt, mom-3/mig-14 (uncloned), mom-5/Fz, dsh-2/Dsh, mig-5/Dsh, kin-19/CKI, gsk-3/GSK3ß, apr-1/APC, wrm-1/3-cat and pop-1/TCF (Figure 4; Lin et al., 1995; Rocheleau et al., 1997; Thorpe et al., 1997; Meneghini et al., 1999; Peters et al., 1999; Rocheleau et al., 1999; Schlesinger et al., 1999; Shin et al., 1999; Bei et al., 2002; Walston et al., 2004). In addition, a parallel pathway involving the kinases MOM-4/Tak1 and LIT-1/Nlk and the binding protein TAP-1/Tab1 interacts with the Wnt pathway to regulate endoderm induction (Meneghini et al., 1999; Rocheleau et al., 1999; Shin et al., 1999). Mutations in almost all of these genes lead to a Mom phenotype (More mesoderm) in which EMS divides to give two MS-like daughters. However, pop-1/TCF mutations cause the opposite phenotype, two E-like daughters (Figure $4)$.

MS, the anterior daughter that produces mesoderm, contains high levels of nuclear POP-1/TCF, while E, the posterior daughter that produces endoderm, contains lower levels of nuclear POP-1/TCF (Lin et al., 1995). In the absence of signal, POP-1/TCF represses target genes (end-1 and end-3) in cooperation with UNC-37/Groucho and HDA-1/histone deacetylase (Calvo et al., 2001). When Wnt ligand binds, activation of both the Wnt and TAK1/NLK pathways leads to formation of a WRM-1/LIT-1 complex that phosphorylates POP-1/TCF, which accumulates in the cytoplasm (Meneghini et al., 1999; Rocheleau et al., 1999; Shin et al., 1999; Maduro et al., 2002; Smit et al., 2004). Recent evidence suggests that LIT-1-dependent phosphorylation of POP-1/TCF creates a binding site for PAR-5, a 14-3-3 protein, and this interaction facilitates POP-1/TCF nuclear export (Lo et al., 2004). After POP-1/TCF export from the E nucleus, other transcription factors (MED-1, MED-2, CBP-1) then activate endoderm-specific target genes (Calvo et al., 2001; Maduro et al., 2002). POP-1/TCF subcellular localization is also regulated by another parallel pathway containing the Src kinase SRC-1 and the inactive receptor tyrosine kinase MES-1 (Bei et al., 2002), and by the acetylation of POP-1/TCF protein by histone acetylases (Gay et al., 2003). 


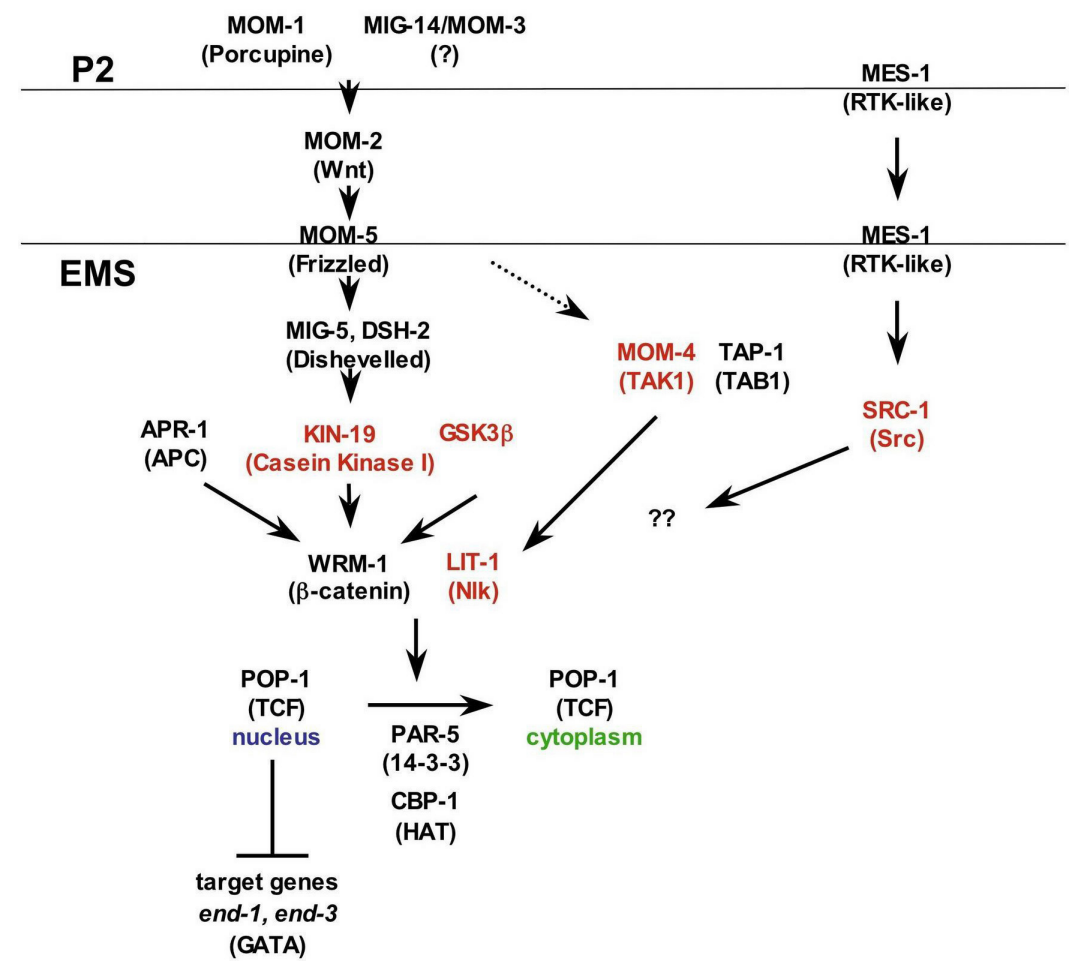

Figure 5. P2-EMS Signaling. Proteins functioning in the noncanonical Wnt pathway and interacting pathways that mediate the P2 signal to EMS are shown. Homologous vertebrate protein names or descriptions are shown in parenthesis. The MIG-14/MOM-3 locus has not been identified yet, but acts in P2. Active kinases are shown in red. The two horizontal lines indicate the plasma membrane of the signaling cell P2 (top line) and of EMS (bottom line). Question marks indicate that the point at which the MES-1/SRC-1 pathway interacts with the Wnt pathway is not yet known. A dashed arrow indicates that Wnt binding may also activate the MOM-4/LIT-1 pathway.

There are several ways in which the pathway acting in endoderm specification is different from a canonical Wnt pathway. First, in this pathway apr-1/APC and $g s k-3 / G S K 3 \beta$ act positively, even though these same factors act in a negative manner in other $C$. elegans processes (compare Figure 3 and Figure 5). The mechanistic explanation for this is currently unknown. Second, is the involvement of lit-1/mom-4 and src-1/mes-1 pathways. There is no evidence yet for these genes functioning in any canonical process in the worm. Finally, the method of regulation of POP-1 is a major difference between this pathway and canonical pathways in other species. In a canonical pathway, TCF acts with other factors to repress transcription until Wnt signaling leads to the formation of a $\beta$-catenin/TCF complex that can activate these target genes. In this worm pathway, POP-1/TCF acts as a transcriptional repressor in the absence of signal, but signaling leads to derepression of target genes via export of POP-1. No evidence for this type of regulation of TCF/LEF proteins has been seen in other species.

\subsection{T cell polarity}

In hermaphrodites, the TL and TR cells of the tail divide asymmetrically to give an anterior daughter (T.a) that generates mostly hypodermal cell fates, and a posterior daughter (T.p) that generates mostly neural fates (phasmid cells) (Sulston and Horvitz, 1977). The asymmetric division of the T cells is controlled by a Wnt pathway involving lin-44/Wnt, lin-17/Fz, lit-1/Nlk, wrm-1/B-cat and pop-1/TCF. lin-44/Wnt is expressed in several tail hypodermal cells posterior to the T cells (Herman et al., 1995). In lin-44/Wnt mutants, the polarity of the T divisions is reversed such that anterior cells adopt neural fates and posterior cells adopt hypodermal fates (Herman and Horvitz, 1994). However, in animals mutant for $l i n-17 / F z$, lit-l/Nlk, and pop-l/TCF, and in animals expressing a dominant-negative POP-1/TCF protein, the asymmetry is abolished and both anterior and posterior progeny adopt hypodermal fates (Sternberg and Horvitz, 1988; Rocheleau et al., 1999; Herman, 2001). The asymmetry in fates is mirrored by an asymmetry in POP-1/TCF: nuclear POP-1/TCF levels are higher in the anterior daughter (T.a) and lower in posterior daughter (T.p). These POP-1/TCF differences are reversed in lin-44/Wnt mutants and abolished in $l i n-17 / F z$ and pop-1/TCF (RNAi) mutants (Herman, 2001). The different phenotype of lin-44/Wnt and lin-17/Fz mutants suggests that a second, anteriorly-expressed Wnt must also function in this process, but this Wnt has not been identified yet. The asymmetric division of the $\mathrm{T}$ cells is likely to be mediated through effects on gene expression, since mutations in components of the NURD (egl-27) and SWI/SNF (psa-1, psa-4, lin-9, lin-35, lin-37) chromatin remodeling 
complexes lead to loss of asymmetry (Herman et al., 1999; Sawa et al., 2000; Cui et al., 2004). A likely target gene is $t$ lp-1, which encodes a $\mathrm{C} 2 \mathrm{H} 2$ zinc finger protein expressed in T.p in a Wnt-dependent manner (Zhao et al., 2002). The novel protein TCL-2, which acts in several other Wnt-mediated processes, also regulates T cell polarity (Zhao et al., 2003).

\subsection{Z1/Z4 polarity}

The bilaterally-symmetric somatic gonad in the hermaphrodite develops from two precursor cells, Z1 and Z4 (Hubbard and Greenstein, 2000). The two gonad arms each have a proximal-distal axis that is defined by an asymmetric first division of Z1 and Z4 into daughter cells with 'proximal' (e.g. anchor cell) and 'distal' (e.g. distal tip cell) fates. The pathway regulating the $\mathrm{Z1} / \mathrm{Z} 4$ asymmetric divisions involves lin-17/Fz, wrm-1/3-cat, lit-1/Nlk and pop-1/TCF, and mutation of these genes leads to a loss of asymmetry and the generation of two daughters with proximal fates (Sternberg and Horvitz, 1988; Miskowski et al., 2001; Siegfried and Kimble, 2002). In this tissue, POP-1/TCF nuclear asymmetry is also present between sister cells, with higher nuclear GFP::POP-1 in proximal $\mathrm{Z1} / \mathrm{Z} 4$ daughters than in distal ones, and this asymmetry is abolished in Wnt pathway mutants (Siegfried et al., 2004). Mutations in the genes sys-1, sys-3, gon-14, gon-15 and gon-16 also show the 'symmetric sisters' phenotype for Z1 and Z4 (Siegfried et al., 2004). However in these five mutants, GFP::POP-1 asymmetry is not lost, suggesting that these genes act downstream or in parallel to the noncanonical Wnt pathway. None of these mutations maps to a region of the genome with known Wnt pathway components. $t c l-2$, which encodes a novel protein, also acts in Z1/Z4 asymmetry (Zhao et al., 2003).

\section{Differences in noncanonical pathways}

There are two significant differences between the three wrm-1/lit-1/pop-1 - dependent noncanonical pathways described above. First, for P2-EMS signaling, loss of pop-1/TCF activity results in two daughters with posterior fates, which is the fate of the cell with lower nuclear POP-1 levels. This makes sense if POP-1 acts as a repressor of the posterior fate. However, for both the Z1/Z4 and T cell asymmetric divisions, loss of pop-1/TCF function results in both daughters adopt the anterior/proximal fate, which is the fate of the cell with higher nuclear POP-1 levels. This suggests that the high levels of POP-1 in the anterior/proximal daughters may be nonfunctional, or that the POP-1 in the posterior/distal daughters is qualitatively different in activity or protein-protein interactions in a manner dependent on Wnt-signaling (for discussion, see (Herman and $\mathrm{Wu}, 2004$ ). This phenomenon is likely related to a second difference, which is that for the $\mathrm{Z} 1 / \mathrm{Z} 4$ and T cell processes, loss of pop-l/TCF gives the same phenotype as loss of $w r m-1 / \beta$-cat or lit-1/Nlk, but for P2-EMS signaling loss of pop-1/TCF activity gives the opposite phenotype. This would be expected if in the former cases Wnt signaling leads to an active, low abundance form of POP-1, while in the latter case Wnt signaling removes active POP-1 from the nucleus. In any case, these results indicate that in $C$. elegans there is variability in how the same components are utilized within noncanonical Wnt signaling pathways.

\section{Other processes utilizing Wnt pathway components}

A number of other developmental processes are known to utilize Wnt pathway components, but the genetic and molecular details of the pathways have not yet been worked out in detail.

\subsection{Spindle reorientation in embryogenesis}

Before the EMS blastomere divides to give MS and E, its centrosomes rotate $90^{\circ}$ from the left/right axis to the anterior/posterior axis (Sulston et al., 1983; Hyman and White, 1987). Blastomere isolation experiments showed that this spindle reorientation also depends on the P2 signal to EMS (Goldstein, 1995). The upstream genes mom-1/porcupine, mom-2/Wnt, mom-5/Fz, kin-19/CKI, and $g s k-3 / G S K 3 \beta$ are required for EMS spindle reorientation, but apr-1/APC, wrm-1/B-cat and pop-1/TCF are not (Schlesinger et al., 1999; Walston et al., 2004). EMS spindle reorientation can still occur when transcription initiation is inhibited. The $s r c-1 / m e s-1$ pathway that acts in endoderm induction also regulates EMS spindle reorientation in parallel to the Wnt pathway (Bei et al., 2002). Together these results suggest that spindle reorientation may be regulated by Wnt-dependent modification of cytoskeletal factors downstream of $g s k-3 / G S K 3 \beta$. Mutations in the same genes listed above for EMS also cause spindle orientation defects in cell of the early AB lineage (Rocheleau et al., 1997; Thorpe et al., 1997; Walston et al., 2004). Spindle reorientation in these cells depends on cell contact with the $C$ blastomere. The Dishevelled genes dsh-1, dsh-2 and mig-5 all function during spindle reorientation for EMS and the AB descendants with $d s h-2$ playing a major role in EMS, but mig-5 having the larger role in the AB lineage (Walston et al., 2004). Note that in spindle reorientation $g s k-3 / G S K 3 \beta$ appears to act positively, rather than as a negative regulator as in the canonical pathway. 
The $\beta$-catenin-independent process of spindle reorientation may represent the first example of a noncanonical Wnt pathway in C. elegans similar to those seen in other species.

\subsection{POP-1 asymmetry in $A B$ embryonic lineages}

In the early embryo, most left/right cell divisions generate daughters with equivalent POP-1/TCF staining, but most anterior/posterior divisions generate an anterior daughter with higher levels of POP-1/TCF than in the posterior daughter (as for EMS, Lin et al., 1998). Loss of pop-1/TCF activity results in cell fate defects in these A/P sister cells. Mutations in wrm- $1 / \beta$-cat and lin-17/Fz can abolish the POP-1/TCF asymmetry in some lineages, suggesting a Wnt pathway mediates the differences in POP-1/TCF levels, as it does in EMS. It was proposed that POP-1/TCF is part of a general A/P coordinate system that can function to distinguish otherwise equivalent sister cells (Lin et al., 1998).

In the $\mathrm{AB}$ lineage, the $\mathrm{POP}-1 / \mathrm{TCF}$ asymmetry between $\mathrm{A} / \mathrm{P}$ sisters depends on contact with the descendants of $\mathrm{P} 1$, and can be induced by contact of early $\mathrm{AB}$ descendants (when there are 8 or fewer $\mathrm{AB}$ descendants) with $\mathrm{E}, \mathrm{MS}$, C, P2 or P3 (Park and Priess, 2003). mom-2/Wnt activity is required in P2 and C, but not MS, to induce this POP-1/TCF asymmetry. mom- $5 / \mathrm{Fz}$ is also required. Interestingly, at later stages (when there are $>32$ progeny from $\mathrm{AB})$ the $\mathrm{AB}$ descendants can divide to generate POP-1/TCF asymmetry without prior contact with P1 descendants, and in the absence of $m o m-2 / W n t$ activity, but $m o m-5 / F z$ and $m o m-4 / T A K 1$ are still required. Recent experiments (Park et al., 2004) showed that membrane-localized MOM-5::GFP is enriched at the posterior pole of these embryonic cells prior to their division, so that the posterior daughter inherits more MOM-5::GFP. AB descendants isolated from the embryo and allowed to divide in culture for several divisions also showed this enrichment of MOM-5::GFP. In both embryos and cultured cells, high MOM-5::GFP levels correlated with low low levels of POP-1/TCF and vice versa. These results suggest that at later times A/P asymmetry for POP-1/TCF either occurs in a Wnt-independent but Frizzled-dependent manner, or utilizes a different Wnt signal generated by the $\mathrm{AB}$ descendents themselves. In some ways this sequential A/P polarization of cell divisions resembles the Wnt/planar cell polarity in flies, except for the involvement of POP-1/TCF in C. elegans. Further work will be required to establish a mechanistic similarity.

\subsection{P7.p polarity}

During vulval development the vulval precursor cells P5.p and P7.p adopt the $2^{\circ}$ fate. The progeny of these two cells adopt the VulA, B, C and D fates, but the polarity of the P5.p and P7.p lineages is mirror symmetric relative to the center of the vulva (ABCD vs. DCBA, Greenwald, 1997; Kornfeld, 1997). Wnt signaling is necessary for P7.p to adopt a polarity opposite that of P5.p. When P5.p and P7.p divide there is an asymmetry in POP-1/TCF levels in the nuclei of their daughters: for P5.p and its descendants, the anterior daughters have higher levels, but this is reversed for P7.p and its descendants (Deshpande et al., 2005). Mutations in the receptors lin-17/Fz and lin-18/Ryk alter the P7.p lineage polarity so that it resembles that of P5.p (Sternberg and Horvitz, 1988; Inoue et al., 2004), and cause a corresponding reversal in POP-1/TCF asymmetry (Deshpande et al., 2005). Genetic redundancy exists for the Wnt signal, since reduction of function of either lin-44 and mom-2, or lin-44 and cwn-2, causes P7.p polarity defects (Inoue et al., 2004). MOM-2/Wnt is expressed in several cells in the region, including the anchor cell, and LIN-44/Wnt is weakly expressed in the anchor cell, suggesting that a gradient of Wnt signals from the anchor cell may regulate P5.p and P7.p lineage polarity. Elegant experiments suggest that LIN-44/Wnt acts through LIN-17/Fz, while MOM-2/Wnt acts through LIN-18/Ryk, indicating that two Wnts acts through different types of Wnt receptors to regulate a common downstream process (Inoue et al., 2004).

\section{4. $1^{\circ}$ lineage of P6.p}

During vulval development, the VPC P6.p adopts the $1^{\circ}$ fate and generates eight cells that fuse to become the VulE and Vul F cells (Greenwald, 1997; Kornfeld, 1997). The four P6.p granddaughters have the fates E-F-F-E, from anterior to posterior. This pattern of fates is disrupted by ablation of the anchor cell and mutations affecting the Ras pathway. In addition, mutation of $l i n-17 / F z$ and lin-18/Ryk disrupts this pattern of fates (Wang and Sternberg, 2000).

\subsection{HSN migration}

The hermaphrodite-specific neurons (HSNs) are born in the posterior of the embryo and migrate anteriorly to the midbody region near the vulva. In cam-1/Ror RTK mutants, the HSNs migrate too far into the anterior (Forrester et al., 1999). The cam-1/Ror overmigration defect is suppressed by mutations in egl-20/Wnt or mig-l/Fz, and is 
phenocopied by excess EGL-20/Wnt expression (Forrester et al., 2004; Kim and Forrester, 2003). The ability of wild-type CAM-1/Ror to rescue the overmigration defect is dependent on the extracellular cysteine rich domain, which is a Wnt binding domains in Frizzled receptors. Overexpression of this domain causes the HSNs to adopt a more posterior location, a phenotype also seen in egl-20/Wnt mutants. These results suggest that a Wnt pathway involving egl-20/Wnt and $m i g-1 / F z$ (but not lin- $17 / F z$, bar-1/ß-cat or pry-1/axin) acts in the HSNs to regulate their migration, and cam-1 interacts antagonistically with this pathway (Forrester et al., 2004).

\subsection{V5 polarity}

The lateral seam cell V5 divides to give an anterior daughter with high nuclear POP-1/TCF that fuses with hyp7, and a posterior daughter with low nuclear POP-1/TCF that becomes a seam stem cell (Lin et al., 1998; Herman, 2001). In egl-20/Wnt mutants, the polarity of this V5 division is reversed 50\% of the time (Whangbo et al., 2000). Other Wnt pathway genes known to act downstream of egl-20/Wnt do not cause this phenotype. Although egl-20/Wnt is expressed in cells posterior to V5 (Whangbo and Kenyon, 1999), it does not appear to directly control the polarity of V5, since expression of egl-20/Wnt in the anterior can rescue the V5 polarity reversal in egl-20/Wnt mutants (Whangbo et al., 2000). The signal that reorients V5 in egl-20/Wnt mutants appears to come from direct contact of V5 with the posterior seam cells V6 and T, since ablation of these cells in egl-20/Wnt mutants restores wild type V5 polarity. The V5 polarity defect in egl-20/Wnt mutants is also suppressed by mutations in $l i n-17 / F z$ and enhanced by a pry-1/axin mutation. Therefore, egl-20/Wnt acts to counteract a signal from neighboring cells that would otherwise cause V5 to divide with a reversed polarity, and this signaling pathway involves $l i n-17 / F z$ and pry-1/axin. Interestingly, global overexpression of egl-20/Wnt leads to a loss of asymmetric division for all the V cells, such that both daughters now adopt the anterior, hyp7 cell fate (Whangbo et al., 2000). It should be pointed out that mutations in cam-1/Ror RTK, which antagonizes egl-20/Wnt function in HSN migration (see above), lead to a V1 polarity defect in the anterior (Forrester et al., 1999).

\subsection{Polarity of other tail cells}

lin-44 encodes a Wnt protein expressed in the posterior hypodermal cells hyp8, hyp9, hyp10 and hyp11 that regulates Wnt signaling in the T cells and P12, acting via the receptor lin-17/Fz (Herman and Horvitz, 1994; Herman et al., 1995; Jiang and Sternberg, 1998). lin-44/Wnt mutants also display defects in asymmetric division and cell fates for the male blast cells B, U and F (Herman and Horvitz, 1994). lin-17/Fz also causes polarity defects in the B cell in males (Sternberg and Horvitz, 1988).

\subsection{Spicule development}

After the initial lin-44/Wnt and lin-17/Fz -dependent asymmetric division of the B cell in males (see above), one sublineage leads to a cell division producing the spicule neuron SPD and its associated non-neuronal sheath cell. In lin-44/Wnt and lin- $17 / \mathrm{Fz}$ mutants, a sheath to neuron cell fate transformation in this sublineage is seen, and two neurons are made (Jiang and Sternberg, 1999). Overexpression of pop-1/TCF in males also leads to this transformation. Together these results suggest a Wnt pathway mediates this asymmetric cell division. A mutation in the son-1 gene causes a similar sheath to neuron transformation (Jiang and Sternberg, 1999). son-1 encodes a widely expressed HMG-box containing protein. son-1 mutants share phenotypes with, and can enhance the phenotypes of, lin-17/Fz mutants for vulval induction $\left(2^{\circ}\right.$ cell fate), somatic gonad morphogenesis and ray production in males. Thus, an HMG-box protein not of the TCF/LEF class, may also regulate Wnt signaling in C. elegans.

\section{Conclusion}

As with other species, Wnt signaling controls a large number of development processes in C. elegans, and the number is still growing. Some of these processes utilize canonical Wnt pathways like those first characterized in Drosophila and vertebrates. Others utilize many of the same components, but act in a noncanonical manner. Curiously, the noncanonical pathway in C. elegans appears different from those in other species (Wnt/Calcium, $\mathrm{Wnt} / \mathrm{PCP}$ ), as it uses both $\beta$-catenin and TCF proteins. To date, one difference between the two types of pathways is the use of BAR-1/ $\beta$-cat in the canonical pathway and WRM- $1 / \beta$-cat in the noncanonical pathway. Related to this, the method of target gene activation by POP-1 differs between pathways.

It will be interesting to determine if simply the identity of the $\beta$-catenin expressed in a cell controls the behavior of the pathway. For many pathways the analysis is still too preliminary to determine which type of pathway is used, but it is quite likely that some of the processes discussed here may act independently of $\beta$-catenin and TCF. Future work may establish that these other types of noncanonical pathways act in the worm, as in other species. 


\section{Acknowledgements}

The work in the Eisenmann lab is supported by grants from the NSF, IBN-9817123 and IBN-0131485, and the NIH GM065424. I thank Julie Gleason, Scott Emmons and anonymous referees for critical reading of the manuscript and Julie Gleason for help with figures.

\section{References}

Austin, J., and Kenyon, C. (1994). Cell contact regulates neuroblast formation in the Caenorhabditis elegans lateral epidermis. Development 120,313-323. Abstract

Bei, Y., Hogan, J., Berkowitz, L.A., Soto, M., Rocheleau, C.E., Pang, K.M., Collins, J., and Mello, C.C. (2002). SRC-1 and Wnt signaling act together to specify endoderm and to control cleavage orientation in early $C$. elegans embryos. Dev. Cell 3, 113-125. Abstract Article

Bourbon, H.M., Aguilera, A., Ansari, A.Z., Asturias, F.J., Berk, A.J., Bjorklund, S., Blackwell, T.K., Borggrefe, T., Carey, M., Carlson, M., et al. (2004). A unified nomenclature for protein subunits of mediator complexes linking transcriptional regulators to RNA polymerase II. Mol. Cell 14, 553-557. Abstract Article

Cadigan, K.M., and Nusse, R. (1997). Wnt signaling: a common theme in animal development. Genes Dev. 11, 3286-3305. Abstract

Calvo, D., Victor, M., Gay, F., Sui, G., Luke, M.P., Dufourcq, P., Wen, G., Maduro, M., Rothman, J., and Shi, Y. (2001). A POP-1 repressor complex restricts inappropriate cell type-specific gene transcription during Caenorhabditis elegans embryogenesis. EMBO J. 20, 7197-7208. Abstract Article

Ch'ng, Q., Williams, L., Lie, Y.S., Sym, M., Whangbo, J., and Kenyon, C. (2003). Identification of genes that regulate a left-right asymmetric neuronal migration in Caenorhabditis elegans . Genetics 164, 1355-1367. Abstract

Chalfie, M., and Sulston, J. (1981). Developmental genetics of the mechanosensory neurons of Caenorhabditis elegans. Dev. Biol. 82, 358-370. Abstract Article

Chalfie, M., Thomson, J.N., and Sulston, J.E. (1983). Induction of neuronal branching in Caenorhabditis elegans. Science 221, 61-63. Abstract

Chow, K.L., and Emmons, S.W. (1994). HOM-C/Hox genes and four interacting loci determine the morphogenetic properties of single cells in the nematode male tail. Development 120, 2579-2592. Abstract

Costa, M., Raich, W., Agbunag, C., Leung, B., Hardin, J., and Priess, J.R. (1998). A putative catenin-cadherin system mediates morphogenesis of the Caenorhabditis elegans embryo. J. Cell Biol. 141, 297-308. Abstract Article

Cui, M., Fay, D.S., and Han, M. (2004). lin-35/Rb cooperates with the SWI/SNF complex to control Caenorhabditis elegans larval development. Genetics 167, 1177-1185. Abstract Article

Deshpande, R., Inoue, T., Priess, J.R., and Hill, R.J. (2005). lin-17/Frizzled and lin-18 regulate POP-1/TCF-1 localization and cell type specification during C. elegans vulval development. Dev. Biol. 278, 118-129. Abstract Article

Eisenmann, D.M., and Kim, S.K. (2000). Protruding vulva mutants identify novel loci and Wnt signaling factors that function during Caenorhabditis elegans vulva development. Genetics 156, 1097-1116. Abstract

Eisenmann, D.M., Maloof, J.N., Simske, J.S., Kenyon, C., and Kim, S.K. (1998). The $\beta$-catenin homolog BAR-1 and LET-60 Ras coordinately regulate the Hox gene lin-39 during Caenorhabditis elegans vulval development. Development 125, 3667-3680. Abstract

Forrester, W.C., Dell, M., Perens, E., and Garriga, G. (1999). A C. elegans Ror receptor tyrosine kinase regulates cell motility and asymmetric cell division. Nature 400, 881-885. Abstract Article 
Forrester, W.C., Kim, C., and Garriga, G. (2004). The C. elegans Ror RTK CAM-1 collaborates with EGL-20/Wnt to regulate cell migration. Genetics. Abstract Article

Gay, F., Calvo, D., Lo, M.C., Ceron, J., Maduro, M., Lin, R., and Shi, Y. (2003). Acetylation regulates subcellular localization of the Wnt signaling nuclear effector POP-1. Genes Dev. 17, 717-722. Abstract Article

Gleason, J.E., Korswagen, H.C., and Eisenmann, D.M. (2002). Activation of Wnt signaling bypasses the requirement for RTK/Ras signaling during C. elegans vulval induction. Genes Dev. 16, 1281-1290. Abstract Article

Goldstein, B. (1992). Induction of gut in Caenorhabditis elegans embryos. Nature 357, 255-257. Abstract Article

Goldstein, B. (1993). Establishment of gut fate in the E lineage of C. elegans: the roles of lineage-dependent mechanisms and cell interactions. Development 118, 1267-1277. Abstract

Goldstein, B. (1995). Cell contacts orient some cell division axes in the Caenorhabditis elegans embryo. J. Cell Biol. 129, 1071-1080. Abstract Article

Greenwald, I. (1997). Development of the Vulva. In C. elegans II, D.L. Riddle, T. Blumenthal, B.J. Meyer and J.R. Priess, ed. (Cold Spring Harbor: Cold Spring Harbor Laboratory Press), pp. 519-541. PubMed

Han, M. (1997). Gut reaction to Wnt signaling in worms. Cell 90, 581-584. Abstract Article

Harris, J., Honigberg, L., Robinson, N., and Kenyon, C. (1996). Neuronal cell migration in C. elegans: regulation of Hox gene expression and cell position. Development 122, 3117-3131. Abstract

Herman, M. (2001). C. elegans POP-1/TCF functions in a canonical Wnt pathway that controls cell migration and in a noncanonical Wnt pathway that controls cell polarity. Development 128, 581-590. Abstract

Herman, M.A. (2003). Wnt Signaling in C. elegans. In Wnt Signaling in Development, M. Kuhl, ed. (Georgetown, TX: Kluwer Academic/Plenum Publishers).

Herman, M.A., Ch'ng, Q., Hettenbach, S.M., Ratliff, T.M., Kenyon, C., and Herman, R.K. (1999). EGL-27 is similar to a metastasis-associated factor and controls cell polarity and cell migration in C. elegans. Development 126, 1055-1064. Abstract

Herman, M.A., and Horvitz, H.R. (1994). The Caenorhabditis elegans gene lin-44 controls the polarity of asymmetric cell divisions. Development 120, 1035-1047. Abstract

Herman, M.A., Vassilieva, L.L., Horvitz, H.R., Shaw, J.E., and Herman, R.K. (1995). The C. elegans gene lin-44, which controls the polarity of certain asymmetric cell divisions, encodes a Wnt protein and acts cell nonautonomously. Cell 83, 101-110. Abstract Article

Herman, M.A., and Wu, M. (2004). Noncanonical Wnt signaling pathways in C. elegans converge on POP-1/TCF and control cell polarity. Front Biosci 9, 1530-1539. Abstract

Hobmayer, B., Rentzsch, F., Kuhn, K., Happel, C.M., von Laue, C.C., Snyder, P., Rothbacher, U., and Holstein, T.W. (2000). WNT signalling molecules act in axis formation in the diploblastic metazoan Hydra. Nature 407, 186-189. Abstract Article

Hoier, E.F., Mohler, W.A., Kim, S.K., and Hajnal, A. (2000). The Caenorhabditis elegans APC-related gene apr-1 is required for epithelial cell migration and Hox gene expression. Genes Dev. 14, 874-886. Abstract

Howard, R.M., and Sundaram, M.V. (2002). C. elegans EOR-1/PLZF and EOR-2 positively regulate Ras and Wnt signaling and function redundantly with LIN-25 and the SUR-2 Mediator component. Genes Dev. 16, 1815-1827. Abstract Article

Hubbard, E.J., and Greenstein, D. (2000). The Caenorhabditis elegans gonad: a test tube for cell and developmental biology. Dev. Dyn. 218, 2-22. Abstract 
Hunter, C.P., Harris, J.M., Maloof, J.N., and Kenyon, C. (1999). Hox gene expression in a single Caenorhabditis elegans cell is regulated by a caudal homolog and intercellular signals that inhibit Wnt signaling. Development 126, 805-814. Abstract

Hyman, A.A., and White, J.G. (1987). Determination of cell division axes in the early embryogenesis of Caenorhabditis elegans. J. Cell Biol. 105, 2123-2135. Abstract Article

Inoue, T., Oz, H.S., Wiland, D., Gharib, S., Deshpande, R., Hill, R.J., Katz, W.S., and Sternberg, P.W. (2004). $C$. elegans LIN-18 is a Ryk ortholog and functions in parallel to LIN-17/Frizzled in Wnt signaling. Cell 118, 795-806. Abstract Article

Jiang, L.I., and Sternberg, P.W. (1998). Interactions of EGF, Wnt and HOM-C genes specify the P12 neuroectoblast fate in C. elegans. Development 125, 2337-2347. Abstract

Jiang, L.I., and Sternberg, P.W. (1999). An HMG1-like protein facilitates Wnt signaling in Caenorhabditis elegans. Genes Dev. 13, 877-889. Abstract

Kaletta, T., Schnabel, H., and Schnabel, R. (1997). Binary specification of the embryonic lineage in Caenorhabditis elegans. Nature 390, 294-298. Abstract Article

Kenyon, C. (1986). A gene involved in the development of the posterior body region of C. elegans. Cell 46, 477-487. Abstract Article

Kim, C., and Forrester, W.C. (2003). Functional analysis of the domains of the $C$ elegans Ror receptor tyrosine kinase CAM-1. Dev. Biol. 264, 376-390. Abstract Article

Kornfeld, K. (1997). Vulval development in Caenorhabditis elegans. Trends Genet 13, 55-61. Abstract Article

Korswagen, H.C. (2002). Canonical and non-canonical Wnt signaling pathways in Caenorhabditis elegans: variations on a common signaling theme. Bioessays 24, 801-810. Abstract Article

Korswagen, H.C., Coudreuse, D.Y., Betist, M.C., van de Water, S., Zivkovic, D., and Clevers, H.C. (2002). The Axin-like protein PRY-1 is a negative regulator of a canonical Wnt pathway in C. elegans. Genes Dev. 16, 1291-1302. Abstract Article

Korswagen, H.C., Herman, M.A., and Clevers, H.C. (2000). Distinct $\beta$-catenins mediate adhesion and signalling functions in C. elegans. Nature 406, 527-532. Abstract Article

Kuhl, M., Sheldahl, L.C., Park, M., Miller, J.R., and Moon, R.T. (2000). The Wnt/Ca2+ pathway: a new vertebrate Wnt signaling pathway takes shape. Trends Genet 16, 279-283. Abstract Article

Lin, R., Hill, R.J., and Priess, J.R. (1998). POP-1 and anterior-posterior fate decisions in C. elegans embryos. Cell 92, 229-239. Abstract Article

Lin, R., Thompson, S., and Priess, J.R. (1995). pop-1 encodes an HMG box protein required for the specification of a mesoderm precursor in early C. elegans embryos. Cell 83, 599-609. Abstract Article

Lo, M.C., Gay, F., Odom, R., Shi, Y., and Lin, R. (2004). Phosphorylation by the $\beta$-catenin/MAPK complex promotes 14-3-3-mediated nuclear export of TCF/POP-1 in signal-responsive cells in C. elegans. Cell 117, 95-106. Abstract Article

Maduro, M.F., Lin, R., and Rothman, J.H. (2002). Dynamics of a developmental switch: recursive intracellular and intranuclear redistribution of Caenorhabditis elegans POP-1 parallels Wnt-inhibited transcriptional repression. Dev. Biol. 248, 128-142. Abstract Article

Maloof, J.N., Whangbo, J., Harris, J.M., Jongeward, G.D., and Kenyon, C. (1999). A Wnt signaling pathway controls hox gene expression and neuroblast migration in C. elegans. Development 126, 37-49. Abstract 
Meneghini, M.D., Ishitani, T., Carter, J.C., Hisamoto, N., Ninomiya-Tsuji, J., Thorpe, C.J., Hamill, D.R., Matsumoto, K., and Bowerman, B. (1999). MAP kinase and Wnt pathways converge to downregulate an HMG-domain repressor in Caenorhabditis elegans. Nature 399, 793-797. Abstract Article

Miskowski, J., Li, Y., and Kimble, J. (2001). The sys- 1 gene and sexual dimorphism during gonadogenesis in Caenorhabditis elegans. Dev. Biol. 230,61-73. Abstract Article

Moghal, N., and Sternberg, P.W. (2003). A component of the transcriptional mediator complex inhibits RAS-dependent vulval fate specification in C. elegans. Development 130, 57-69. Abstract Article

Natarajan, L., Witwer, N.E., and Eisenmann, D.M. (2001). The divergent Caenorhabditis elegans $\beta$-catenin proteins BAR-1, WRM-1 and HMP-2 make distinct protein interactions but retain functional redundancy in vivo. Genetics 159, 159-172. Abstract

Park, F.D., and Priess, J.R. (2003). Establishment of POP-1 asymmetry in early C. elegans embryos. Development 130, 3547-3556. Abstract Article

Park, F.D., Tenlen, J.R., and Priess, J.R. (2004). C. elegans MOM-5/frizzled functions in MOM-2/Wnt-independent cell polarity and is localized asymmetrically prior to cell division. Curr. Biol. 14, 2252-2258. Abstract Article

Peifer, M., and Polakis, P. (2000). Wnt signaling in oncogenesis and embryogenesis--a look outside the nucleus. Science 287, 1606-1609. Abstract Article

Peters, J.M., McKay, R.M., McKay, J.P., and Graff, J.M. (1999). Casein kinase I transduces Wnt signals. Nature 401, 345-350. Abstract Article

Polakis, P. (2000). Wnt signaling and cancer. Genes Dev. 14, 1837-1851. Abstract

Rocheleau, C.E., Downs, W.D., Lin, R., Wittmann, C., Bei, Y., Cha, Y.H., Ali, M., Priess, J.R., and Mello, C.C. (1997). Wnt signaling and an APC-related gene specify endoderm in early C. elegans embryos. Cell 90, 707-716. Abstract Article

Rocheleau, C.E., Yasuda, J., Shin, T.H., Lin, R., Sawa, H., Okano, H., Priess, J.R., Davis, R.J., and Mello, C.C. (1999). WRM-1 activates the LIT-1 protein kinase to transduce anterior/posterior polarity signals in C. elegans. Cell 97, 717-726. Abstract Article

Ruvkun, G., and Hobert, O. (1998). The taxonomy of developmental control in Caenorhabditis elegans. Science 282, 2033-2041. Abstract Article

Salser, S.J., and Kenyon, C. (1992). Activation of a C. elegans Antennapedia homologue in migrating cells controls their direction of migration. Nature 355, 255-258. Abstract Article

Salser, S.J., and Kenyon, C. (1996). A C. elegans Hox gene switches on, off, on and off again to regulate proliferation, differentiation and morphogenesis. Development 122, 1651-1661. Abstract

Sawa, H., Kouike, H., and Okano, H. (2000). Components of the SWI/SNF complex are required for asymmetric cell division in C. elegans. Mol. Cell 6, 617-624. Abstract Article

Sawa, H., Lobel, L., and Horvitz, H.R. (1996). The Caenorhabditis elegans gene lin-17, which is required for certain asymmetric cell divisions, encodes a putative seven-transmembrane protein similar to the Drosophila frizzled protein. Genes Dev. 10, 2189-2197. Abstract

Schlesinger, A., Shelton, C.A., Maloof, J.N., Meneghini, M., and Bowerman, B. (1999). Wnt pathway components orient a mitotic spindle in the early Caenorhabditis elegans embryo without requiring gene transcription in the responding cell. Genes Dev. 13, 2028-2038. Abstract

Shackleford, G.M., Shivakumar, S., Shiue, L., Mason, J., Kenyon, C., and Varmus, H.E. (1993). Two Wnt genes in Caenorhabditis elegans. Oncogene 8, 1857-1864. Abstract 
Shin, T.H., Yasuda, J., Rocheleau, C.E., Lin, R., Soto, M., Bei, Y., Davis, R.J., and Mello, C.C. (1999). MOM-4, a MAP kinase kinase kinase-related protein, activates WRM-1/LIT- 1 kinase to transduce anterior/posterior polarity signals in C. elegans. Mol. Cell 4, 275-280. Abstract Article

Siegfried, K.R., Kidd, A.R., III, Chesney, M.A., and Kimble, J. (2004). The sys-1 and sys-3 genes cooperate with Wnt signaling to establish the proximal-distal axis of the Caenorhabditis elegans gonad. Genetics 166, 171-186. Abstract Article

Siegfried, K.R., and Kimble, J. (2002). POP-1 controls axis formation during early gonadogenesis in C. elegans. Development 129, 443-453. Abstract

Smit, L., Baas, A., Kuipers, J., Korswagen, H., van de Wetering, M., and Clevers, H. (2004). Wnt activates the Tak1/Nemo-like kinase pathway. J. Biol. Chem. 279, 17232-17240. Abstract Article

Sternberg, P.W., and Horvitz, H.R. (1988). lin-17 mutations of Caenorhabditis elegans disrupt certain asymmetric cell divisions. Dev. Biol. 130, 67-73. Abstract Article

Sulston, J.E., Albertson, D.G., and Thomson, J.N. (1980). The Caenorhabditis elegans male: postembryonic development of nongonadal structures. Dev. Biol. 78, 542-576. Abstract Article

Sulston, J.E., and Horvitz, H.R. (1977). Post-embryonic cell lineages of the nematode, Caenorhabditis elegans. Dev. Biol. 56, 110-156. Abstract Article

Sulston, J.E., Schierenberg, E., White, J.G., and Thomson, J.N. (1983). The embryonic cell lineage of the nematode Caenorhabditis elegans. Dev. Biol. 100, 64-119. Abstract Article

Sulston, J.E., and White, J.G. (1980). Regulation and cell autonomy during postembryonic development of Caenorhabditis elegans. Dev. Biol. 78, 577-597. Abstract Article

Thorpe, C.J., Schlesinger, A., Carter, J.C., and Bowerman, B. (1997). Wnt signaling polarizes an early C. elegans blastomere to distinguish endoderm from mesoderm. Cell 90, 695-705. Abstract Article

Veeman, M.T., Axelrod, J.D., and Moon, R.T. (2003). A second canon. Functions and mechanisms of $\beta$-catenin-independent Wnt signaling. Dev. Cell 5, 367-377. Abstract Article

Walston, T., Tuskey, C., Edgar, L., Hawkins, N., Ellis, G., Bowerman, B., Wood, W., and Hardin, J. (2004). Multiple Wnt signaling pathways converge to orient the mitotic spindle in early C. elegans embryos. Dev. Cell 7, 831-841. Abstract Article

Wang, M., and Sternberg, P.W. (2000). Patterning of the C. elegans $1^{\circ}$ vulval lineage by RAS and Wnt pathways. Development 127, 5047-5058. Abstract

Waring, D.A., and Kenyon, C. (1990). Selective silencing of cell communication influences anteroposterior pattern formation in C. elegans. Cell 60, 123-131. Abstract Article

Waring, D.A., and Kenyon, C. (1991). Regulation of cellular responsiveness to inductive signals in the developing C. elegans nervous system. Nature 350, 712-715. Abstract Article

Waring, D.A., Wrischnik, L., and Kenyon, C. (1992). Cell signals allow the expression of a pre-existent neural pattern in C. elegans. Development 116, 457-466. Abstract

Whangbo, J., Harris, J., and Kenyon, C. (2000). Multiple levels of regulation specify the polarity of an asymmetric cell division in C. elegans. Development 127, 4587-4598. Abstract

Whangbo, J., and Kenyon, C. (1999). A Wnt signaling system that specifies two patterns of cell migration in $C$. elegans. Mol. Cell 4, 851-858. Abstract Article

Wodarz, A., and Nusse, R. (1998). Mechanisms of Wnt signaling in development. Annu. Rev. Cell Dev. Biol. 14, 59-88. Abstract Article 
Zhang, H., and Emmons, S.W. (2000). A C. elegans mediator protein confers regulatory selectivity on lineagespecific expression of a transcription factor gene. Genes Dev. 14, 2161-2172. Abstract Article

Zhang, H., and Emmons, S.W. (2001). The novel C. elegans gene sop-3 modulates Wnt signaling to regulate Hox gene expression. Development 128, 767-777. Abstract

Zhao, X., Sawa, H., and Herman, M.A. (2003). tcl-2 encodes a novel protein that acts synergistically with Wnt signaling pathways in C. elegans. Dev. Biol. 256, 276-289. Abstract Article

Zhao, X., Yang, Y., Fitch, D.H., and Herman, M.A. (2002). TLP-1 is an asymmetric cell fate determinant that responds to Wnt signals and controls male tail tip morphogenesis in C. elegans. Development 129, 1497-1508. Abstract

All WormBook content, except where otherwise noted, is licensed under a Creative Commons Attribution License 